\title{
Frequency of Needlestick Injury with Associated Risk Factors and Knowledge about Blood Borne Transmitted Diseases among Health Care Workers in Alnoor Specialist Hospital, Makkah, Saudi Arabia
}

\author{
Waleed Alzahrani ${ }^{1}$, YassirAlmatrafi ${ }^{2}$, YassirAlzahrani $^{3}$, YazeedAlahmadi $^{4}$, Emad Allehyani $^{5}$, \\ Ahmad Alahmadi ${ }^{6}$, Waleed Azab $^{7}$, Abdulaziz Alluhaibi ${ }^{8}$

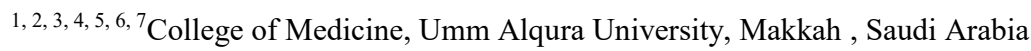 \\ ${ }^{8}$ Ibn Sina National College for Medical Studies, Jeddah, Saudi Arabia
}

\begin{abstract}
Background: Needlestick and Sharps injuries (NSSIs) are wounds caused by sharps such as hypodermic needles, blood collection needles, intravenous cannulas or needles. Needlestick and sharps injuries (NSSIs) are one of the major risk factors for bloodborne infection among the health-care facilities. They are considered to be the single greatest hazard to medical personnel. Objectives: To determine the frequency of NSSI with associated risk factors among health care workers in OR and ER departments of Alnoor Specialist Hospital and to assess level of the knowledge about blood borne transmitted diseases. Material and methods: A cross-sectional study conducted among Health Care Workers of Alnoor Specialist Hospital, Makkah, Saudi Arabia from $9^{\text {th }}$ of August to $28^{\text {th }}$ of October 2015 with participation of $168 \mathrm{HCWs}$. A modified EPINet questionnaire used to determine the frequency and associated risk factors of NSSI. Results: Out of 168 participants, 61(36.3\%) experienced Needlestick injuries at least once during working in a medical field; 85.2 $\%$ of them were vaccinated for hepatitis $B .36 \%$ of injuries occurred during recapping of needle. Conclusion: Health Care Workers are at risk of needlestick injury. Malpractice of Universal Precautions especially with recapping of used needles lead to needlestick injury. NSSI can be avoided by practice of Universal Precautions and introduce an educational program.
\end{abstract}

Keywords: Needlestick, blood borne, Alnoor Specialist Hospital

\section{Introduction}

Depending on the World Health Organization, around 3 million of heath care workers out of 35 million experience NSSIs every year. Two million of those injuries was contaminated with HBV, 0.9 million was contaminated with HCV and 170, 000 with HIV. More than $90 \%$ of these infections occur in developing country. The WHO estimated that exposure to sharps in the workplace accounts for $40 \%$ of infection with $\mathrm{HBV}$ and $\mathrm{HCV}$ and $2 \%-3 \%$ of HIV infections among HCWs.Following NSI, the risk of transmission from infected patients to $\mathrm{HCW}$ are $3-10 \%$ for hepatitis $\mathrm{B}, 3 \%$ for hepatitis $\mathrm{C}$, and $0.3 \%$ for HIV.

Makkah city as a holy place where Muslims from all around the world come for religious purposes. Alnoor Specialist Hospital has high capacity in ER and OR departments with different specialties serving citizens and people who come for Umrah and Hajj.

Our study will be conducted among HCWs in OR and ER departments in Alnoor Specialist Hospital because those staffs care for patients in stressful conditions and deal with sharp objects more frequently.

\section{Aim of the Study}

To provide up to date information on NSSI in Alnoor Specialist Hospital and to introduce an educational program in order to increase awareness about risk of NSSIs

\section{Objectives}

1) To determine the frequency of NSSI with associated risk factors among health care workers in OR and ER departments of Alnoor Specialist Hospital and King Faisal Hospital

2) To assess level of the knowledge about blood borne transmitted

\section{Material and Methods}

Study design

A cross- sectional study will be conducted among health care workers of Alnoor Specialist Hospital and King Faisal Hospital

Study population

Emergency and Operating rooms staffs will be targeted . HCWs in ER include physicians, interns, nurses, cleaners and paramedics, with the exclusion of $\mathrm{HCW}$ who are on vacation and doctors who come to ER department for consultation from other departments. The OR HCWs include Surgeons, interns, Anesthesiologists, anesthesia staffs, Nurses, and Cleaners. With exclusion of those who are on vacation.HCWs of OR and ER departments will be identified from OR and ER administration records offices.

Study Sample

All HCWs in ER and OR departments will be included in this study at the time of data collection 


\section{International Journal of Science and Research (IJSR) \\ ISSN (Online): 2319-7064}

Index Copernicus Value (2015): 78.96 | Impact Factor (2015): 6.391

Measurement tool:

A modified EPINetquestionnaire will be used to determine the frequency and associated risk factors of NSSI. The questionnaire will be given to HCWs during breaks and recollected at the same time or next four day for almostone month duration for data collection.

\section{Data Analysis}

Data entry and analysis will be carried out after data collection using SPSS.

\section{Results}

Table 1: Age of Health Care Workers in Alnoor Specialist Hospital, Makkah, 2015

\begin{tabular}{|c|c|c|}
\hline$A G E$ & $N$ & $\%$ \\
\hline$<25$ & 10 & 5.95 \\
\hline $25-35$ & 111 & 66.07 \\
\hline$>35$ & 47 & 27.98 \\
\hline Range & $20-58$ \\
\hline Mean \pm SD & $32.178 \pm 6.909$ \\
\hline
\end{tabular}

Table 2: Gender of Health Care Workers in Alnoor Specialist Hospital, Makkah, 2015

\begin{tabular}{|l|c|c|}
\hline \multicolumn{1}{|c|}{$S E X$} & $N$ & $\%$ \\
\hline - Male & 79 & 47.0 \\
\hline - Female & 89 & 53.0 \\
\hline
\end{tabular}

Table 3: Job category of Health Care Workers Participants in Alnoor Specialist Hospital, Makkah , 2015

\begin{tabular}{|ll|c|c|}
\hline \multicolumn{2}{|c|}{ Job category } & $N$ & $\%$ \\
\hline - & ER Physician & 20 & 11.90 \\
\hline - & Surgeon & 36 & 21.43 \\
\hline - & Anesthesiologist & 6 & 3.57 \\
\hline - & Anesthesia technician & 11 & 6.55 \\
\hline - & Nurse & 89 & 52.98 \\
\hline - & Intern & 6 & 3.57 \\
\hline
\end{tabular}

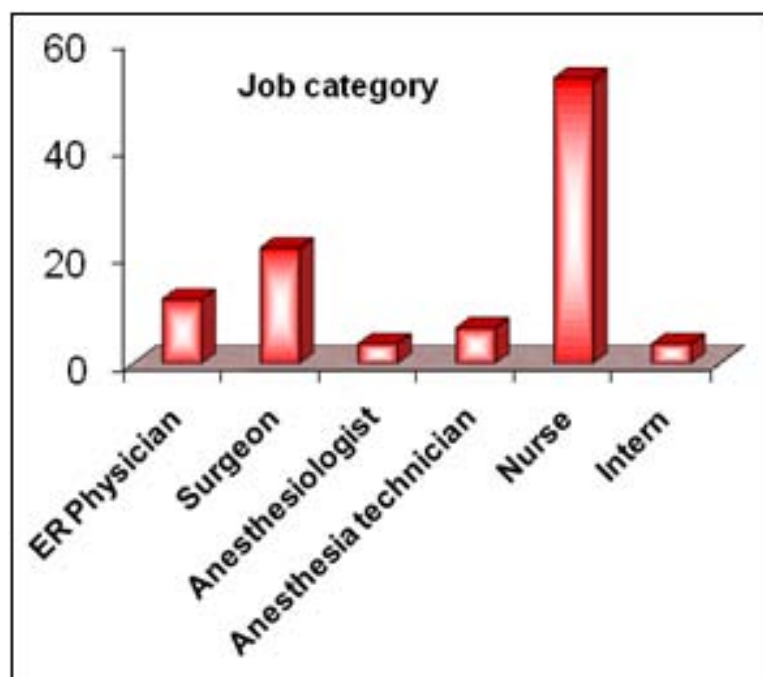

Figure 1: Job category of Health Care WorkersParticipants in Alnoor Specialist Hospital, Makkah , 2015

52.98\% of Health Care Workers Participants were Nurses while $21.43 \%$ Surgeon and $11.9 \%$ ER Physician.
Table 4: Duration of working in a medical field of Health Care WorkersParticipants in Alnoor Specialist Hospital, Makkah, 2015

\begin{tabular}{|l|c|c|}
\hline Duration of working in a medical field (years) & $N$ & $\%$ \\
\hline - Less than 1 yr & 22 & 13.1 \\
\hline - $1-5$ yrs & 55 & 32.7 \\
\hline - $6-9$ yrs & 45 & 26.8 \\
\hline - More than 10 yrs & 46 & 27.4 \\
\hline
\end{tabular}

Most of Health Care Workers $p$ Participants have experience of 1-5yrs in a medical field $32.7 \%$

Table 5: Department of Health Care WorkersParticipants in Alnoor Specialist Hospital, Makkah, 2015

\begin{tabular}{|l|c|c|}
\hline \multicolumn{1}{|c|}{ Department } & $\mathrm{N}$ & $\%$ \\
\hline$\bullet$ ER & 79 & 47.02 \\
\hline$\bullet$ OR & 89 & 52.98 \\
\hline
\end{tabular}

Most of Health Care Workers Participants were from OR $52.98 \%$

Table 6: Duration of working in this hospital of Health Care WorkersParticipants in Alnoor Specialist Hospital, Makkah, 2015

\begin{tabular}{|c|c|c|}
\hline Duration of working in this hospital (years) & $N$ & $\%$ \\
\hline - Less than 1 yr & 53 & 31.5 \\
\hline - $1-5 \mathrm{yrs}$ & 55 & 32.7 \\
\hline - $6-9 \mathrm{yrs}$ & 36 & 21.4 \\
\hline - $\quad$ More than 10 yrs & 24 & 14.3 \\
\hline
\end{tabular}

Most of Health Care Workers Participants worked at Alnoor Specialist Hospital for (1-5 yrs) 32.7\% .

Table 7: Occurrence of needle stick injury (NSI)/sharps injury to Health Care WorkersParticipants in Alnoor Specialist Hospital, Makkah, 2015

\begin{tabular}{|c|c|c|}
\hline Occurrence of needle stick injury (NSI)/sharps injury & $N$ & $\%$ \\
\hline Yes & 61 & 36.3 \\
\hline No & 107 & 63.7 \\
\hline Total & 168 & 100.00 \\
\hline
\end{tabular}

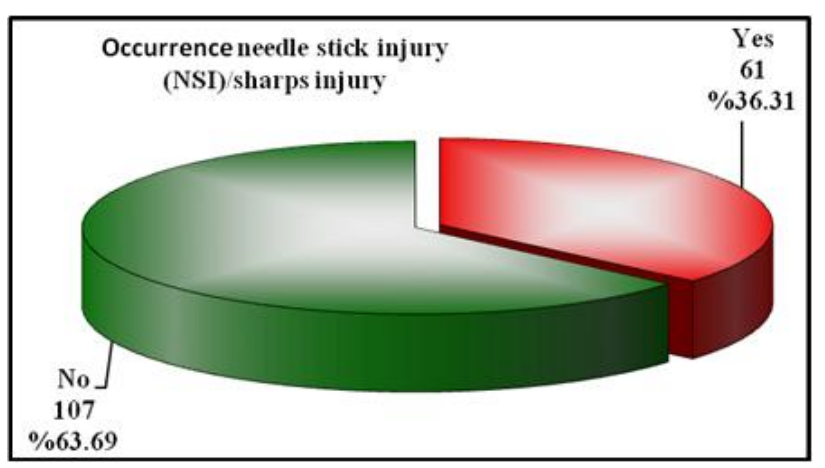

Figure 2: Occurrence of needle stick injury (NSI)/sharps injury to Health Care WorkersParticipants in Alnoor Specialist Hospital, Makkah, 2015

Table 8: Frequency of needle stick injury (NSI) /sharps injury of Health Care WorkersParticipants in Alnoor Specialist Hospital, Makkah, 2015

\begin{tabular}{|l|c|c|}
\hline Frequency of needle stick injury (NSI) /sharps injury & $N$ & $\%$ \\
\hline - One time & 27 & 44.3 \\
\hline - 2-5 times & 28 & 45.9 \\
\hline - 6-9 times & 4 & 6.6 \\
\hline - More than 10 times & 2 & 3.3 \\
\hline
\end{tabular}

\section{Volume 6 Issue 1, January 2017 www.ijsr.net}


$45.9 \%$ of Health Care Workers Participantshad NSI more than once (2-5 times)

Table 9: Procedure during needle stick injury of Health Care WorkersParticipants in Alnoor Specialist Hospital, Makkah, 2015

\begin{tabular}{|l|c|c|}
\hline \multicolumn{1}{|c|}{ procedure during needle stick injury } & $N$ & $\%$ \\
\hline Recapping of needle & 22 & 36.1 \\
\hline Improper disposal of needle & 4 & 6.6 \\
\hline Overflowing containers/ Sharps Bin & 1 & 1.6 \\
\hline Passing of instrument / handling devices & 2 & 3.3 \\
\hline IV Canulation/Setting IV line & 8 & 13.1 \\
\hline Venepuncture (Collecting blood) & 4 & 6.6 \\
\hline $\begin{array}{l}\text { Administration of IV drugs or blood or IM or } \\
\text { subcutaneous injection or intradermal injections }\end{array}$ & 5 & 8.2 \\
\hline Checking blood sugar using a glucometer & 4 & 6.6 \\
\hline Suturing & 14 & 23.0 \\
\hline Concealed sharps/after disposal of needle & 0 & 0.0 \\
\hline Clean up/cleaning & 1 & 1.6 \\
\hline Restless patient & 2 & 3.3 \\
\hline Splash of body fluids/blood & 0 & 0.0 \\
\hline Collision or bumped into other member of staff & 0 & 0.0 \\
\hline Withdrawing injection fluid or drugs & 2 & 3.3 \\
\hline Operation/surgery & 20 & 32.8 \\
\hline & &
\end{tabular}

Most of Health Care Workers Participants injuries occure during Recapping of needle (36.1\%).

Table 10: Hepatits B Vaccination status at the time of injury of Health Care Workers Participants in Alnoor Specialist Hospital, Makkah, 2015

\begin{tabular}{l|c|c|}
\hline Hepatits B Vaccination status at the time of injury & $N$ & $\%$ \\
\hline - Completed Hepatitis B vaccine [3doses] & 52 & 85.2 \\
\hline - Incomplete Hepatitis B vaccine [1-2 doses received] & 3 & 4.9 \\
\hline - Not immunized at all & 4 & 6.6 \\
\hline - Not received any Hepatitis B vaccination & 2 & 3.3 \\
\hline $85.2 \%$ of Health Care Workers Participants Completed \\
Hepatitis B vaccine [3doses]
\end{tabular}

Table 11: Last injury of Health Care WorkersParticipants in Alnoor Specialist Hospital, Makkah, 2015

\begin{tabular}{|l|c|c|}
\hline last injury & $N$ & $\%$ \\
\hline - Last 1yr & 35 & 57.4 \\
\hline - Last 2-5yrs & 17 & 27.9 \\
\hline - Last 6-9yrs & 6 & 9.8 \\
\hline - $10 y r s$ or more & 3 & 4.9 \\
\hline
\end{tabular}

$57.4 \%$ of Health Care Workers Participants had injury in last 1 year

\section{Discussion}

This is cross-sectional study done at Alnoor Specialist Hospital, Makkah, Saudi Arabia from $9^{\text {th }}$ of August to $28^{\text {th }}$ of October 2015 with participation of $168 \mathrm{HCWs}$. In order to asses the frequency of NSSI with associated risk factors among health care workers.

Out of 168 participants, 61(36.3\%) experienced Needlestick injuries at least once during working in a medical field.

Most of participants were in the age group of (25-35).The mean age of the HCWs was $(32.1 \pm 6.9)$ years. The age range was between 20 and 58 years. It was found that majority of the HCWs participants were females $89(52.98 \%)$.

There was a significant difference in case prevalence of needles stick injury among various job categories, 89 $(52.98 \%)$ were working as nurses followed by $36(21.43 \%)$ as surgeons and 20(11.9\%) as ER Physicians. The common place of occurrence of needles stick injury was in Operation Room - 89 (52.98\%); followed by Emergency department $79(48.02 \%)$.

$45.9 \%$ of Health Care Workers Participants had NSI more than once (2-5 times) which could be due to lack of experience or weak knowledge.35 (57.4\%) of them had Needle stick injuries in the past 1 year.The doctors and interns had better knowledge regarding the diseases spread through NSI when compared with nurses.

$65.4 \%$ of injured HCWs have poor practice regarding NSSI . $73.8 \%$ of all participants have good knowledge about blood borne transmitted diseases. The most common circumstances during which the Needle stick injuries occurred was while recapping of needle (36\%). $85.2 \%$ of Health Care Workers Participants were vaccinated for hepatitis B.

\section{Conclusion and Recommendation}

Needle stick injuries can be preventable if safety is followed in the work place. An effective system for disposing of used needles and sharps is crucial to preventing injuries. These injuries can be avoided by eliminating the unnecessary use of needles, using devices with safety features, and promoting education and safe work practices for handling needles and related systems.

- Health workers who may come in contact with blood or body fluids should receive hepatitis B vaccinations.

- Follow all safety procedures in the workplace.

- Regularly undertake safety refresher courses.

- Minimise use of needles.

- latex gloves don't protect you against needlestick injuries.

- Don't bend or snap used needles.

- Never re-cap a used needle.

- Place used needles into a clearly labelled and punctureproof sharps approved container.

\section{Acknowledgement}

The authors express their appreciation to DrAmr Hassan(Department of Internal Medicine, College of Medicine, Umm Alqura University, Makkah, Saudi Arabia), who provided guidance for analysis and contributing in its review at different stages. Acknowledgements are also due to various colleagues for their valuable comments.

\section{References}

[1] World Health Organization. The World Health Report 2002-Reducing Risks, Promoting Healthy Life. Geneva: World Health Organization.

\section{Volume 6 Issue 1, January 2017




\section{International Journal of Science and Research (IJSR) \\ ISSN (Online): 2319-7064}

Index Copernicus Value (2015): 78.96 | Impact Factor (2015): 6.391

[2] Kelen GD, Fritz SF, Qaqish B. Unrecognized HIV infection in Emergency Department patients N Engl. 1988; 318: 1645-1650

[3] Wilburn SQ, Eijkemans G. Preventing needlestick injuries among healthcare workers: A WHO-ICN collaboration. Int J Occup Environ Health 2004;10:4516.

[4] Yacoub R, Al Ali R, Moukeh G, Lahdo A, Mouhammad Y, Nasser M. Hepatitis B vaccination status and needlestick injuries among healthcare workers in Syria. J Global Infect Dis. 2010 Jan-Apr;2(1):28-34.

[5] E. Nasiri, M. Vahedi, H. Siamian, Y. Mortazavi and H. Jafari . Needle Sticks Injury with Contaminated Blood in the Special Unit, S Staff. Middle-East Journal of Scientific Research 5 (2): 61-64, 2010

[6] Saulatjahan . Epidemiology of needle stick injuries among health care workers in secondary care hospital in Saudi Arabia. Annals of Saudi Medicine. 2005;25(3):233-238

[7] MaqboolAlam. KNOWLEDGE, ATTITUDE AND PRACTICES AMONG HEALTH CARE

[8] WORKERS ON NEEDLE-STICK INJURIES. Annals of Saudi Medicine, Vol 22, Nos 5-6, 2002

[9] Alysia Giani (2012) EPINet ${ }^{\mathrm{TM}}$ Report: Needle Stick Injury Incidents Are High SAFE: 6 